\title{
The energetic and survival costs of Varroa parasitism in honeybees
}

\author{
Patricia AldeA ${ }^{1,2,3}$, Francisco Bozinovic ${ }^{2}$ \\ ${ }^{1}$ Facultad de Agronomía e Ingeniería Forestal, Pontificia Universidad Católica de Chile, Santiago, Chile \\ ${ }^{2}$ Center of Applied Ecology and Sustainability (CAPES), Facultad de Ciencias Biológicas, Pontificia Universidad \\ Católica de Chile, Santiago, Chile \\ ${ }^{3}$ Corporación Apícola Chile, Región de O'Higgins, Mostazal, Chile
}

Received 25 October 2019 - Revised 15 April 2020 - Accepted 28 May 2020

\begin{abstract}
The ectoparasite $V$. destructor is one of the major threats to Western honeybees' production (A. mellifera ) worldwide, causing colony losses and reducing bees' productivity and pollinating capacity. Since parasitism produces high energy consumption in hosts, the aim of this study was to compare the effects of this ectoparasite on energy expenditure and survival rate in honeybees. Newborn bees were kept in chambers at $32{ }^{\circ} \mathrm{C}$ and 55\% humidity with food ad libitum. Individual bees were taken at random and grouped into three treatments: $T_{0}$ (no mites), $T_{1}$ (one mite), and $T_{2}$ (two mites). After the mites had fed on the bees, the metabolic rate $\left(\mathrm{CO}_{2}\right.$ production $=\mathrm{VCO}_{2}$ ) was individually measured at $32{ }^{\circ} \mathrm{C}$ for $3 \mathrm{~h}$. We also measured survival rate, using the same groups for 8 days. A significant effect of the number of mites on $\mathrm{VCO}_{2}$ was found $\left(T_{0}=3.14 \mu \mathrm{LCO}_{2} \mathrm{~min}^{-1}, T_{1}=\right.$ $4.03 \mu \mathrm{LCO}_{2} \mathrm{~min}^{-1}$ and $\left.T_{2}=6.44 \mu \mathrm{LCO}_{2} \min ^{-1}, F_{(2)}=25.81, p<0.001\right)$. The treatments did not affect significantly the bees' survival $\left(p=0.283\right.$ ), despite the survival rates recorded were $57.5 \%$ in $T_{0}, 42.5 \%$ in $T_{1}$, and $40.0 \%$ in $T_{2}$. $V$. destructor clearly increases the energetic cost of living in bees and provoking a reduction of the survival rate even when this value was not significant statistically.
\end{abstract}

\section{metabolic rate / survival / parasitism / energetic costs / Varroa destructor}

\section{INTRODUCTION}

The importance of the Western honeybee, Apis mellifera, as a pollinator and the impact of this function on crop and seed production in agricultural ecosystems are well-known (Klein et al. 2017). A decline has been noted in honeybee populations since 2006, as a result of different threats around the word (Kang et al. 2016; Le Conte et al. 2010; Nazzi and Le Conte 2016; Neumann and Carreck 2010; Ramsey et al. 2019; Ratnieks and Carreck 2010).

Corresponding author: P. Aldea, plaldea@uc.cl Manuscript Editor: James Nieh
The most widespread threat in beekeeping is the ectoparasitic mite Varroa destructor (Acari: Mesostigmata), which is present almost in every beekeeping country even in Australia since June 2016 (OIE 2019). It causes more damage than all other known apicultural diseases and parasites (Emsen et al. 2015; Evans and Cook 2018; Locke et al. 2014; Maggi et al. 2016). This ectoparasite affects individual bees and the colony as a whole because it feeds actively on the host, consuming the fat body (Ramsey et al. 2019) and the hemolymph of adult and immature bees (Nazzi and Le Conte 2016; Richards et al. 2011). It also acts as a vector of viruses, bacteria, and fungi (Annoscia et al. 2012). In the long term, this ectoparasite affects the Darwinian fitness of bees, causing important economic losses and degrading 
the functioning of the ecosystem (Boncristiani et al. 2012; Fries et al. 2006; Klein et al. 2017; Ramsey et al. 2019; Schmid-Hempel 2008).

In the case of honeybees, a wide range of physical, physiological, and behavioral changes has been described in adult bees parasitized during the pupal phase (Annoscia et al. 2012; Erban et al. 2019; Genersch and Michel 2010; Kralj and Fuchs 2006; Lee et al. 2010; Schäfer et al. 2010; Yang and Cox-Foster 2007). Mites feed on the brood during their reproductive phase (Nazzi and Le Conte 2016) and during their phoretic phase (Ramsey et al. 2018, 2019) but the importance of this last point is unclear (Nazzi and Le Conte 2016). Without treatment, most colonies in temperate climates die within 1-3 years (Ramsey and van Engelsdorp 2016; Rosenkranz et al. 2010).

Due to the success of Varroa in parasitizing honeybees, studies must focus on its physiological significance and its implications (Nazzi and Le Conte 2016). Knowledge of changes in the host's energy allocation in response to parasites is crucial for understanding the impact of the parasite on both individuals and populations (Garrido et al. 2016; Kutzer and Armitage 2016; Schmid-Hempel 2008, 2009). One way to measure integrative physiological variables is through the standard metabolic rate (SMR), which represents the energetic cost of living at a given temperature (Kovac et al. 2007, 2014). The metabolic rate in bees and other insects is affected by age (Kovac et al. 2007; Stabentheiner et al. 2003), race (Stabentheiner and Kovac 2014), level of activity (Hartfelder et al. 2013), ambient temperature (DeVries et al. 2016), body mass (DeVries et al. 2016; Stabentheiner and Kovac 2014), and health status (Bordier et al. 2016; Kralj and Fuchs 2010; Luong et al. 2017; Schmid-Hempel 2008), among other factors. For instance, the energy expenditure of young bees at rest increases with the ambient temperature fourteen times when the temperature move between 10 and $40{ }^{\circ} \mathrm{C}$, but it is several times below the values for highly active bees (Blatt and Roces 2001; Kovac et al. 2007; Stabentheiner et al. 2003). According to Blatt and Roces (2001), a high level of activity could provoke a decrease in trehalose in the bee hemolymph reaching the maximal capacity of the fat body to synthesize trehalose.
Studies on energy have been conducted in healthy bees at different ages or activity levels and at different temperatures (Hartfelder et al. 2013; Stabentheiner et al. 2010). However, there is no report on the energetic cost of living in diseased honeybees, except some inferences respecting bees infested with Nosema ceranae (Alaux et al. 2014; Bordier et al. 2016; Kralj and Fuchs 2010; Naug 2014). Clearly, organisms living in large groups, such as honeybees inside hives, are particularly vulnerable to parasite transmission and disease (Klein et al. 2017; Kurze et al. 2016), as occur when a colony has been exposed to Varroa destructor . Detrimental effects of parasitism on host fitness are usually attributed to parasite-associated disturbances to host energy budgets (Agnew et al. 2000; Careau et al. 2010), sometimes provoking changes in the metabolic rate of the resting host (Robar et al. 2011). Luong et al. (2017) showed that when fruit flies (Drosophila hydei) were exposed directly to the ectoparasitic mite Macrocheles muscaedomesticae, their energy expenditure increased by $35 \%$ compared to flies with indirect contact, and to more than double the energy expenditure of uninfected flies. This is explained by the activation of the immune system, which might interfere with energy turnover or signaling mechanisms (Klein et al. 2017); the cost would result from maintaining defenses in a state of readiness (Bozinovic et al. 2013; Catalán et al. 2011, 2012a, b; Moret and Schmid-Hempel 2000; Schmid-Hempel 2008), reducing another component of the host's fitness (Ardia et al. 2012; Otálora-Ardila et al. 2016). This trade-off between different fitness components leads to differences in how much defense is used (Frank and Schmidt-Hempfel 2008). However, it is known that Varroa destructor activates the transforming growing factor beta or TGF- $\beta$ induced pathways in the bee to suppress wound healing and part of the immune response, and that the collective action of stressors intensifies these effects (Erban et al. 2019).

In this work, we tested the effect of mites on the energy expenditure of individual honeybees under laboratory conditions. We also tested whether and by how much the survival rate in individual honeybees is affected by the number of mites. 


\section{MATERIALS AND METHODS}

Honeybees (Apis mellifera) were kept in an apiary with six colonies located in Mediterranean agroecosystems of Central Chile $\left(34^{\circ} 03^{\prime} \mathrm{S} ; 70^{\circ}\right.$ $\left.41^{\prime} \mathrm{W}\right)$; this apiary applies strict sanitary control for all diseases, especially against Varroa destructor, to ensure healthy bees with an infestation rate lower than $2 \%$. A second apiary with three colonies located at our laboratory $\left(33^{\circ} 22^{\prime} \mathrm{S}\right.$; $70^{\circ} 36^{\prime} \mathrm{W}$ ) is managed to have mites, so in this case, no treatment was applied, and worker or drone brood production was stimulated to obtain a major number of mites from each frame. During the late spring and summer of 2017-2018, we obtained worker brood frames from the healthy colonies and moved them to a climate-controlled chamber at an ambient temperature ( $\left.T_{\text {Acclim }}\right)$ of 32 $\pm 1.2{ }^{\circ} \mathrm{C}$, humidity $55 \pm 5 \%$, and photoperiod L:D $=0: 24$ (Hartfelder et al. 2013). The worker brood remained in the chamber for the last 5 or 6 days as sealed brood. Emerged bees were kept in small, randomly grouped units of one hundred and fed with 50\% sugar syrup and amino acids/vitamins (Promotor L®) solution for 6-10 days before use in the study. We conducted in vivo assays, selecting 30 honeybees from different units and assigning them at random to each of three treatment groups: (a) group $T_{0}(0$ mites, control group), (b) group $T_{1}$ (single honeybee treated with 1 mite), and (c) group $T_{2}$ (single honeybee treated with 2 mites). At the same time, we preserved infested brood (worker and drone brood) in a second chamber under the same conditions to rear mites according to Dietermann et al. (2013). We obtained mites from sealed brood selecting only darker females. Before starting each assay, enough mites were obtained to apply the treatments in each group of bees. The mites were kept in Petri dishes in a chamber for at least $3 \mathrm{~h}$ to make them hungry (Dietermann et al. 2013).

\subsection{Metabolic rate}

Honeybees were weighed in an analytical balance ( $\pm 0.0001 \mathrm{~g} ; \mathrm{JK}-180$, Chyo, Kyoto) and we used only bees between 85 and $110 \mathrm{mg}$. Then one or two mites were placed directly on each bee with a brush ( $T_{1}$ and $T_{2}$ groups). The bee was left alone and without movement in an Eppendorf tube in the chamber for $1 \mathrm{~h}$ to obtain direct, effective parasitization. We made constantly visual inspections to try to identify if the mite fed or not on the bees (for instance, change in bee behavior or localization of the mite on the bee), if not, we remove the mite or if was necessary, we used a new bee and mite. In the case of the control group, the same procedure was followed but without mites. Ten resting bees per treatment were used, defining a resting bee as "no or only small visible signs of activity like small movements of antennae or single legs" (Kovac et al. 2007). After that, the rates of $\mathrm{CO}_{2}$ production $\left(\mathrm{VCO}_{2}\right)$ were determined using an open-flow system consisting of a glass metabolic chamber as suggested by Lighton (2008) and Lighton and Halsey (2011). Each honeybee was placed in the metabolic chamber and this was placed in a temperaturecontrolled incubator at $32{ }^{\circ} \mathrm{C}$ for $3 \mathrm{~h}$. Air was drawn from the environment and $\mathrm{CO}_{2}$ was scrubbed with a Drierite column; then $\mathrm{VCO}_{2}$ was recorded continuously (Hartfelder et al. 2013; Lighton 2008). The sample passed directly to the $\mathrm{CO}_{2}$ analyzer (Sable system) with a flow of $150 \mathrm{ml} / \mathrm{min}$. Data were transformed from percentage to volume per min and the total $\mathrm{CO}_{2}$ production per individual was calculated with the EXPEDATA program (Sable Systems) (Chappell and Rogowitz 2000; Hartfelder et al. 2013). During all process, bees were restricted in water and food supply. With this information, a relationship was calculated for each treatment group between $\mathrm{VCO}_{2}$ and number of mites (Kovac et al. 2007; Stabentheiner et al. 2012).

\subsection{Survival}

To measure the survival probability, single bees were exposed to parasitization by 0,1 , or 2 mites in Petri dishes with supply of sugar syrup and water ad libitum. Each sample was kept in a chamber under the same conditions as before $(T$ Acclim $=32 \pm 1.2{ }^{\circ} \mathrm{C}$, humidity $=55 \pm 5 \%, \mathrm{~L}: \mathrm{D}=$ $0: 24)$. The viability of the mite was checked every day. Any mite that was in poor condition like low reaction with a brush, limited mobility, or if it was not on the bee, was removed and replaced with a new one. The survival test was performed over a 
total of 8 days' observation with 10 bees per treatment and 4 repetitions each. A total of 40 bees were included in each treatment.

\subsection{Statistical analyses}

Statistical analyses were performed using the STATISTICA® (2001) version 6.0 statistical package for Windows ${ }^{\circledR}$. To compare the metabolic rate data, we used a one-way ANOVA and a posteriori Tukey test for multiple comparisons. Data fulfilled the assumptions of the tests. The predictor variable was the number of mites and the dependent variable was the metabolic rate, $\mathrm{VCO}_{2}\left(\mu \mathrm{L} \min ^{-1}\right)$. Results are reported as mean and standard errors (SE).

For survival data, a Kaplan and Meier test was performed first for each treatment to obtain the survival probability, being 0 for censored and 1 for alive cases by day and treatment $(0,1$ or 2 mites, as grouped variable). Then, a Log-Rank test was applied subsequently to determine whether the differences between all groups were significant or if a separate comparison between control groups versus each infested group was it.

\section{RESULTS}

\subsection{Metabolic rate}

Mean $\mathrm{VCO}_{2}$ was $3.14 \pm 0.34 \mu \mathrm{LCO}_{2} \min ^{-1}$ in the control group (ranged between 2.12-4.26 $\left.\mu \mathrm{LCO}_{2} \min ^{-1}\right), 4.03 \pm 0.34 \mu \mathrm{LCO}_{2} \min ^{-1}$ in the $T_{1}$ group (2.59-4.91 $\left.\mu \mathrm{LCO}_{2} \mathrm{~min}^{-1}\right)$, and $6.44 \pm$ $0.34 \mu \mathrm{LCO}_{2} \min ^{-1}$ in the $T_{2}$ group (4.59-8.15 $\left.\mu \mathrm{LCO}_{2} \min ^{-1}\right)$. The ANOVA test revealed that the number of mites significantly affected $\mathrm{VCO}_{2}$ in each bee $\left(F_{(1,27)}=25.81, p<0.000001\right)$ but the a posteriori Tukey's test revealed that the difference is significant only between $T_{0}$ and $T_{2}$ and between $T_{1}$ and $T_{2}$ (Figure 1). Although, the metabolic rate in bees treated with one Varroa increased on average by 1.3 times in comparison to the control group, the main effect is observed between bees with $T_{2}$ versus $T_{0}$ group (it increased on average by 2.0 times, producing 3.30 $\mu \mathrm{LCO}_{2} \min ^{-1}$ more than the control group), and between $T_{2}$ versus $T_{1}$ group (increasing on average $2.41 \mu \mathrm{LCO}_{2} \mathrm{~min}^{-1}$ more).

\subsection{Survival}

Figure 2 shows the results of survival probability obtained between groups. After the Kaplan and Meier test, the survival probability obtained is $57.5 \%$ in the control group $\left(T_{0}\right), 42.5 \%$ in $T_{1}$ and $40.0 \%$ in $T_{2}$. Even when the probability of survival is $15 \%\left(T_{1}\right)$ to $17.5 \%\left(T_{2}\right)$ less than in bees without Varroa, this difference is statistically not significant according to the Log-Rank test ( $p=0.283$ ). If we compare between $T_{0}$ and the infested bees, the Log-Rank test is not significant for $T_{1}(p=0.519)$ as for $T_{2}(p=0.133)$ group.

\section{DISCUSSION}

The effect of parasitism in its broadest sense involves metabolic changes in the host, reduction in the growth rate of juveniles and decreasing survival of hosts (Agnew et al. 2000; Careau et al. 2010). Our experiment illustrates at physiological and life-history levels how the parasite Varroa destructor plays a large, if not the largest, role in the high rate of colony losses registered around the world (Evans and Cook 2018; Klein et al. 2017; Ramsey and van Engelsdorp 2016; Ramsey et al. 2018; Requier et al. 2018). Our results strongly suggest the importance of mites feeding on adult bees in the non-reproductive phase. Our main results can be summarized as follows: Varroa provokes an effect on the metabolism of resting bees (Frank and SchmidtHempfel 2008; Luong et al. 2017; Sadd and Schmid-Hempel 2009; Schmid-Hempel 2008); as expected, the presence and number of mites significantly affect the energetic cost of living by increasing the metabolic rate in resting bees (Schmid-Hempel 2008; Luong et al. 2017), as other bee parasites do (Alaux et al. 2014; Bordier et al. 2016; Kralj and Fuchs 2010; Naug 2014). These results contradict Robar et al. (2011), who did not detect an effect on the metabolic rate of hosts, although this does not reflect an absence of parasite-associated effects on the host's metabolic rate within systems. As mentioned above, the metabolic c (Bozinovic et al. 2013; Catalán et al. 2011, 2012a, b; Hartfelder et al. 2013; Kovac et al. 2007; Stabentheiner et al. 2003; Stabentheiner et al. 2010; Stabentheiner and 


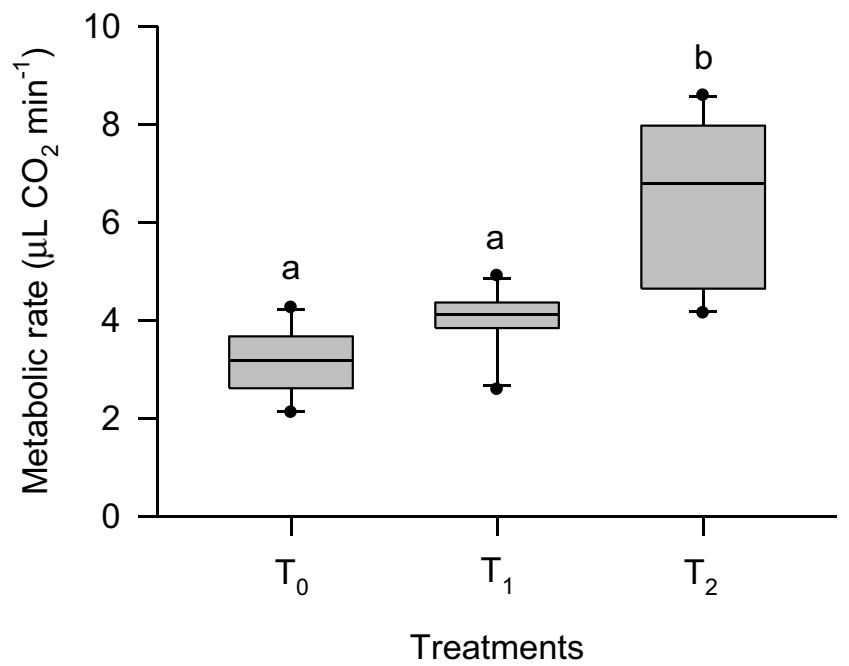

Figure 1. Effect of different numbers of the ectoparasite Varroa destructor on the metabolic rate of honeybees. Values are reported as mean $\pm 1 \mathrm{SD}$. Letters beside symbols refer to significant differences at $p<0.05$ within each treatment group using a post hoc Tukey's test for multiple comparison. Groups were $T_{0}=$ no mite, $T_{1}=$ one mite, $T_{2}$ $=$ two mites.

Kovac 2014; Luong et al. 2017; Schmid-Hempel 2008). The bees in this study were of the same age and race, kept at the same temperature, with no activity, and no signs of disease at the beginning of the assays. Our results for the control group bees $\left(T_{0}\right)$ were similar to those found in healthy, middle-aged bees (Blatt and Roces 2001; Kovac et al. 2007, 2014; Stabentheiner and Kovac 2014); however, the energy cost increased in parasitized host bees as happens in chipmunks $(\sim 7.6 \%$ more for each parasite) or flies ( $\sim 35 \%$ more) (Careau et al. 2010; Luong et al. 2017; Naug 2014). No reports were found for metabolic rates in bees infested by $V$. destructor, therefore no data were available for comparison; the metabolic rate in our bees was close to that of bees measured at $40{ }^{\circ} \mathrm{C}$

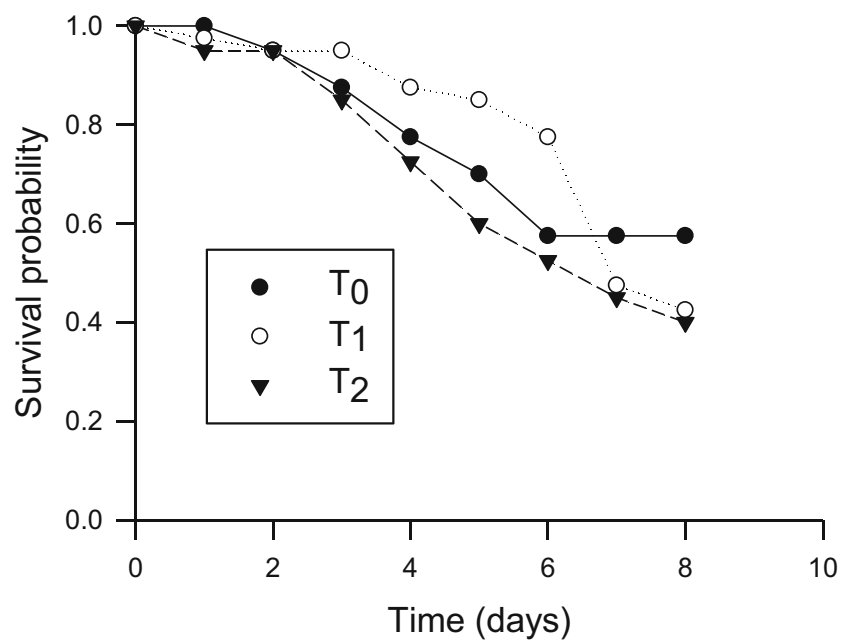

Figure 2. Survival rate between treatments using Kaplan-Meier Test with different loads of Varroa destructor over time (days). Treatments were as follows: $T_{0}=$ no mite, $T_{1}=$ one mite, $T_{2}=$ two mites (see text). 
by Stabentheiner et al. (2003). When the parasite affects a single bee or an entire colony, there is an energy cost which will vary according to infestation level, virus presence, nutrition, external stress factors, age, race, beekeeping management, immune system activation, etc. (Agnew et al. 2000; Careau et al. 2010; Emsen et al. 2015; Erban et al. 2019; Locke et al. 2014; Sadd and SchmidHempel 2009; Rosenkranz et al. 2010). The final effect is a reduction in the fitness of the family, and the major colony losses explained by the presence of $V$. destructor (Kurze et al. 2016; Kang et al. 2016; Neumann and Carreck 2010; Ramsey et al. 2019). Infestation induces high energy expenditure (increased energy turnover according to the number of parasites) and overuse of fat body (Blatt and Roces 2001), generating an allocation of energy to activation of the immune system (Bozinovic et al. 2013; Catalán et al. 2011, 2012a, b; Garrido et al. 2016; Luong et al. 2017; Moret and Schmid-Hempel 2000; SchmidHempel 2008); the quantities of some enzymes are decreased or increased in the wounding process and foraging compounds are injected during parasitism (Ardia et al. 2012; Koleoglu et al. 2017; Otálora-Ardila et al. 2016; Żółtowska et al. 2005). Additionally, parasitized bees weigh less, have a lower protein content, and suffer a drastic reduction in longevity (Nazzi and Le Conte 2016; Ramsey and van Engelsdorp 2016). When Varroa mites feed on bees, they extract lipids or fatty acids from the feeding wounds that they scrape into the host (Evans and Cook 2018), affecting their reserves of energy (Ramsey et al. 2018; Ramsey et al. 2019) or their energyproducing capacity (Blatt and Roces 2001). As Figure 2 shows, the survival probability of single honeybees is not significantly different between control group and infested bees maybe due to the small samples size, but it is possible to see a reduction of survival probability when more parasites are present (Alaux et al. 2014; Bordier et al. 2016; Kralj and Fuchs 2006, 2010; Naug 2014). These results agree with previous reports on mortality rates in colonies parasitized by Varroa destructor (Lee et al. 2010; Schäfer et al. 2010; Rosenkranz et al. 2010).

Apart from our physiological data, no reports were found about the effect of Varroa on bees' individual survival. We adopted this approach because $V$. destructor is the only threat to honeybees that increases the risk of other pathogens, pesticides, and poor resources in their environment (Evans and Cook 2018). Overall, the number of mites increases the energetic cost of living in single honeybees, we hypothesized that this happened probably through activation of the immune system and direct damage to fat body, resulting in a survival cost. The metabolic cost of immune system activation is nearly $30 \%$ in insects (Ardia et al. 2012) and could be higher in vertebrates (Careau et al. 2010; Otálora-Ardila et al. 2016). Thus, in our case, the immune response triggered by the Varroa mite entails a higher cost of maintenance and corresponding fitness (survival) costs.

It has previously been recommended in practical beekeeping to control Varroa mites due to the risk of virus transmission, keeping the number below a certain economic threshold. These findings confirm the importance of keeping Varroa numbers low because of the direct effects of parasitization.

Summarizing, the energy cost for the bee is higher when it is parasitized, increasing by 1.3 and 2.00 times when the individual has one and two mites, respectively. This means more energy expenditure related to the number of mites on each bee.

The survival probability was not significantly affected by the number of mites but the survival is reduced by $15 \%$ and $17.5 \%$ when the bees are parasitized with one or two mites, respectively.

\section{ACKNOWLEDGMENTS}

We are grateful to ANID PIA/BASAL FB0002, FONDECYT 1190007 to FB, and to colleagues from CAPES and CEAPIMAYOR for logistic support.

\section{AUTHORS' CONTRIBUTION}

Both authors contributed to the writing, preparation, and data analysis of this manuscript.

\section{COMPLIANCE WITH ETHICAL STANDARDS}


Conflict of interest The authors declare that they have no conflict of interest.

Les coûts énergétique et de survie du parasitisme du Varroa chez les abeilles

taux métabolique / survie / parasitisme / coûts énergétiques / Varroa destructor.

Die Energie- und Überlebenskosten des Varroaparasitismus bei Honigbienen.

\section{Metabolismusrate / Überleben / Parasitismus / energetische Kosten / Varroa destructor.}

\section{REFERENCES}

Agnew, P., Koella, JC. and Michalakis, Y. (2000) Review: Host life history responses to parasitism. Microbes Infect., 2: 891-896. DOI: https://doi.org/10.1016 /S1286-4579(00)00389-0.

Alaux, C., Crauser, D., Pioz, M., Saulnier, C., LeConte, Y. (2014) Parasitic and immune-modulation of flight activity in honey bees tracked with optical counters. J. Exp. Biol. 217, 3416-3424.

Annoscia, D., Del Piccolo, F. and Nazzi, F. (2012) How does the mite Varroa destructor kill the honeybee Apis mellifera? Alteration of cuticular hydrocarbons and water loss in infested honeybees. J. Insect Physiol. 58: 1548-1555. DOI: https://doi.org/10.1016/j. jinsphys.2012.09.008.

Ardia, DR., Gantz, JE., Schneider, BC. and Strebel, S. (2012) Costs of immunity in insects: and induced immune response increases metabolic rate and decreases antimicrobial activity. Funct. Ecol. 26: $732-$ 739.

Blatt, J. and Roces, F. (2001) Haemolymph sugar levels in foraging honeybees (Apis mellifera carnica): dependence on metabolic rate and in vivo measurement of maximal rates of trehalose synthesis. J. Exp. Biol. 204, 2709-2716.

Boncristiani H., Underwood R., Schwarz R., Evans J.D., Pettis J., vanEngelsdorp D. (2012) Direct effect of acaricides on pathogen loads and gene expression levels in honey bees Apis mellifera. J. Insect Physiol. 58: 613-620.

Bordier, C., Pioz, M., Crauser, D., Le Conte, Y. and Alaux, C. (2016). Should I stay or should I go?: honeybee drifting behaviour as a function of parasitism. Apidologie. DOI: https://doi.org/10.1007/s13592016-0475-1.
Bozinovic, F., Catalán, TP. and Kalergis, AM. (2013) Immunological vulnerability and adjustments to environmental thermal variability. Rev. Chil. Hist. Nat. $86: 475-483$.

Careau, V., Thomas, DW., Humphries, MM. (2010) Energetic cost of bot fly parasitism in free-ranging eastern chipmunks. Oecologia 162: 303-312. DOI: https://doi. org/10.1007/s00442-009-1466-y.

Catalán, TP., Barceló, M., Niemeyer, HM., Kalergis, AM. and Bozinovic F. (2011) Pathogen and diet-dependent foraging, nutritional and immune ecology in mealworms. Evol. Ecol. Res. 13:711-723.

Catalán, TP., Wozniak, A., Niemeyer, HM., Kalergis, AM. and Bozinovic, F. (2012a) Interplay between thermal and immune ecology: effect of environmental temperature on insect immune performance and energetic costs after immune challenge. J. Insect Physiol. 58:310-317.

Catalán, TP., Niemeyer, HM., Kalergis, AM. and Bozinovic, F. (2012b) Interplay between behavioural thermoregulation and immune response in mealworms. J. Insect Physiol. 58: 1450-1455.

Chappell, MA. and Rogowitz, GL. (2000) Mass, temperature and metabolic effects on discontinuous gas exchange cycles in eucalyptus-boring beetles (Coleoptera, Cerambycidae). J. Exp. Biol. 203: 3809-3820.

DeVries, ZC., Kells, S. and Appel, A. (2016). Estimating the critical thermal maximum (CTmax) of bed bugs, Cimex lectularius : Comparing thermo limit respirometry with traditional visual methods. Comp. Biochem. Physiol., A. DOI: https://doi.org/10.1016/j. cbpa.2016.03.003.

Dietermann, V., Nazzi, F., Martin, S., Anderson, D., Locke, B., Delaplane, K., Wauquiez, Q., Tannahill, C., Frey, E., Ziegelmann, B., Rosenkranz, P., Ellis, J. (2013) Standard Methods for Varroa Research. In V. Dietemann; JD. Ellis; P. Neumann (Eds) The COLOSS BEEBOOK, Volume II: Standard Methods for Apis mellifera pest and pathogen research. Journal of Apicultural Research 52(1). DOI: https://doi. org/10.3896/IBRA.1.52.1.0.

Emsen, B., Hamiduzzaman, M., Goodwin, P. and GuzmanNovoa, E. (2015) Lower Virus Infections in Varroa destructor-Infested and Uninfested Brood and Adult Honey Bees (Apis mellifera) of a Low Mite Population Growth Colony Compared to a High Mite Population Growth Colony. PLoS ONE 10 (2): e0118885.doi:https://doi.org/10.1371/journal. pone.0118885.

Erban, T., Sopko, B., Kadlikova, K., Talacko, P. and Haran, K. (2019) Varroa destructor parasitism has a greater effect on proteome changes than the deformed wing virus and activates TGF- $\beta$ signaling pathways. Nature Scientific Report 9:9400. DOI: https://doi. org/10.1038/s41598-019-45764-1.

Evans J. and Cook S. (2018) Genetics and physiology of Varroa mites. Curr. Opin. Insect Sci.: 26: 130- 135. DOI: https://doi.org/10.1016/j.cois.2018.02.005.

Frank, S.A. and Schmidt-Hempfel, P. (2008) REVIEW Mechanisms of pathogenesis and the evolution of 
parasite virulence. J. Evol. Biol. 21 (2008) 396- 404. DOI: https://doi.org/10.1111/j.14209101.2007.01480.x.

Fries I., Anton, I., Rosenkranz, P. (2006) Survival of mite infested (Varroa destructor) honey bee (Apis mellifera) colonies in a Nordic climate. Apidologie 37: 564-570.

Garrido M., Hochman, V., Pnini, M., Abramsky, Z., Krasnov, B., Gutman, R., Kronfeld-Schor, N. and Hawlena, H. (2016) Time budget, oxygen consumption and body mass responses to parasites in juvenile and adult wild rodents Parasit. Vectors 9:120 DOI: https://doi.org/10.1186/s13071-016-1407-7.

Genersch, E. and Michel, A. (2010) Emerging and reemerging viruses of the honey bee (Apis mellifera L.). Vet. Res.. 41 (54).

Hartfelder, K., Bitondi, M., Brent, C., GuidugliLazzarini, K., Simões, Z., Stabentheiner, A., Tanaka, E. and Wang, Y. (2013) Standard methods for physiology and biochemistry research in Apis mellifera. J. Apic. Res. 52(1). DOI: https://doi.org/10.3896 /IBRA.1.52.1.06.

Kang, Y., Blanco, K., Davis, T., Wang, Y. and DeGrandiHoffman, G. (2016) Disease dynamics of honeybees with Varroa destructor as parasite and virus vector. Math. Biosci. 275 (2016): 71- 92. DOI: https://doi. org/10.1016/j.mbs.2016.02.012.

Klein S., Cabirol, A., Devaud, J.M., Barron, A. and Lihoreau, M. (2017) Why Bees Are So Vulnerable to Environmental Stressors. Trends Ecol. Evol.. DOI: https://doi.org/10.1016/j.tree.2016.12.009.

Koleoglu, G., Goodwin, P., Reyes-Quintana, M., Hamiduzzaman, M. and Guzman-Novoa, E. (2017) Effect of Varroa destructor, Wounding and Varroa Homogenate on Gene Expression in Brood and Adult Honey Bees, PLoS ONE. DOI: https://doi.org/10.1371 /journal.pone.0169669.

Kovac, H., Stabentheiner A., Hetz S., Petz M. and Crailsheim, K. (2007) Respiration of resting honeybees. J. Insect Physiol. 53: 1250-1261.

Kovac, H., Kâfer, H., Stabentheiner, A. and Acosta, C. (2014) Metabolism and upper thermal limits of Apis mellifera carnica and A. m. ligustica. Apidologie 45: 664- 677.

Kralj, J. and Fuchs, S. (2006) Parasitic Varroa destructor mites influence flight duration and homing ability of infested Apis mellifera foragers. Apidologie 37: 577 587.

Kralj, J. and Fuchs, S. (2010) Nosema sp. influences flight behavior of infected honey bee (Apis mellifera) foragers. Apidologie 41: $21-28$.

Kurze, C., Routtu, J. and Moritz, R. (2016) Review: Parasite resistance and tolerance in honeybees at individual and social level. Zoology 119: 290- 297.

Kutzer, M. and Armitage, S. (2016) Maximizing fitness in the face of parasites: a review of host tolerance. Zoology 119: 281- 289.

Le Conte, Y., Ellis, M., Ritter, W. (2010) Varroa mites and honey bee health: can Varroa explain part of the colony losses? Apidologie 41 (3). DOI: https://doi. org/10.1051/apido/2010017.

Lee, KV., Moon, RD., Burkness, EC., Hutchison, WD., and Spivak, M. (2010) Practical sampling plans for Varroa destructor (Acari:Varroidae) in Apis mellifera (Hymenoptera:Apidae) colonies and apiaries, J. Econ. Entomol. 103: 1039-1050.

Lighton, JRB. (2008) Measuring metabolic rates. Oxford University Press; New York.

Lighton, JRB. and Halsey, LG. (2011) Flow-through respirometry applied to chamber systems: pros and cons, hints and tips. Comp. Biochem. Physiol. A158: 265275. DOI: https://doi.org/10.1016/j.cbpa.2010.11.026.

Locke, B., Forsgren, E. and de Miranda, JR. (2014) Increased Tolerance and Resistance to Virus Infections: A Possible Factor in the Survival of Varroa destructor Resistant Honey Bees (Apis mellifera). PLoS ONE 9(6): e99998. DOI: https://doi.org/10.1371/journal. pone.0099998.

Luong, L., Horn, C. and Brophy, T. (2017) Mite cost: Energetic cost of parasite avoidance and infection. Physiol. Biochem. Zool. 90(4):471-477. q 2017 by The University of Chicago. DOI: https://doi. org/10.1086/691704.

Maggi, M., Antúnez, K., Invernizzi, C., Aldea, P., Vargas, M. et al. (2016) Honeybee health in South America. Apidologie 47:835-854. DOI: https://doi.org/10.1007 /s13592-016-0445-7.

Moret, Y. and Schmid-Hempel, P. (2000) Survival for Immunity: The Price of Immune System Activation for Bumblebee Workers. Science 290, 1166- 1168. DOI: https://doi.org/10.1126/science.290.5494.1166.

Naug, D. (2014) Infected honeybee foragers incur a higher loss in efficiency than in the rate of energetic gain. Biol. Lett.. 10, 20140731. DOI: https://doi. org/10.1098/rsbl.2014.0731.

Nazzi, F. and Le Conte, Y. (2016) Ecology of Varroa destructor, the Major Ectoparasite of the Western Honey Bee, Apis mellifera. Annu. Rev. Entomol. 2016. 61:417-32. DOI: 10.1146/annurev-ento010715-023731.

Neumann, P. and Carreck, N. (2010) Honey bee colony losses. J. Apic. Res. 49(1): 1-6. DOI: https://doi. org/10.3896/IBRA.1.49.1.01.

OIE 2019. Sanitary report of Varroosis. Available in: https://www.oie.int/wahis_2/public/wahid. $\mathrm{php} /$ Diseaseinformation/statuslist.

Otálora-Ardila, A., Gerardo Herrera L.M., José Juan Flores-Martínez, and Kenneth C. Welch, Jr. (2016) Metabolic Cost of the Activation of Immune Response in the Fish-Eating Myotis (Myotis vivesi): The Effects of Inflammation and the Acute Phase Response PLoS One. 11(10): e0164938.

Ramsey, S. and van Engelsdorp, D. (2016). Varroa Mites: Beekeeper Enemy Number 1. Mellifera 16(1): 1-3.

Ramsey, S., Gulbronson, C., Mowery, J., Ochoa, R., van Engelsdorp, D. and Bauchan, G. (2018) A MultiMicroscopy Approach to Discover the Feeding Site and Host Tissue Consumed by Varroa destructor on 
Host Honey Bees. Microsc. Microanal.. 24 (Suppl 1): 1258- 1259. DOI: https://doi.org/10.1017 /S1431927618006773.

Ramsey, S., Ochoa, R., Bauchan, G., Gulbronson, C., Mowery J., et al. (2019). Varroa destructor feeds primarily on honey bee fat body tissue and not hemolymph. PNAS 29 (116): 1792- 1801. DOI: 10.1073/ pnas.1818371116.

Ratnieks, F. and Carreck, N. (2010) Clarity on Honey Bee Collapse? Science 327 (5962): 152- 153. DOI: https://doi.org/10.1126/science.1185563.

Requier, F., Antúnez, K., Morales, C., Aldea Sánchez, P., Castilhos, D. et al. (2018) Trends in beekeeping and honey bee colony losses in Latin America. J. Apic. Res. DOI: https://doi.org/10.1080/00218839.2018.1494919.

Richards, E.H., Jones, B. and Bowman, A. (2011) Salivary secretions from the honeybee mite, Varroa destructor: Effects on insect haemocytes and preliminary biochemical characterization, Parasitology 138 (2011) 602-608.

Robar, N., Murray, D. Burness, G. et al. 2011. Effects of parasites on host energy expenditure: the resting metabolic rate stalemate. Can. J. Zool.. 89: 1146-1155. DOI: https://doi.org/10.1139/Z11-084.

Rosenkranz, P., Aumeier, P. and Ziegelmann, B. (2010) Biology and control of Varroa destructor. J. Invertebr. Pathol. 103: 96-119.

Sadd, B. and Schmid-Hempel, P. (2009) PERSPECTIVE Principles of ecological immunology. Journal compilation 2008 Blackwell Publishing Ltd. 2. DOI: https://doi.org/10.1111/j.1752-4571.2008.00057.x.

Schäfer, O.M., Ritter, W., Pettis, J.S. and Neumann, P. (2010) Winter losses of honeybee colonies (Hymenoptera: Apidae): The role of Infestations with Aethina tumida (Coleoptera: Nitidulidae) and Varroa destructor (Parasitiformes: Varroidae). J. Econ. Entomol. 103 (1): 10-16.

Schmid-Hempel, P. (2008) Parasite immune evasion: a momentous molecular war. Trends Ecol. Evol., 23(6): 318-326.
Schmid-Hempel, P. (2009) Immune defence, parasite evasion strategies and their relevance for "macroscopic phenomena" such as virulence. Philos. Trans. R. Soc. B. 364: 85-98. DOI: https://doi.org/10.1098 /rstb.2008.0157.

Stabentheiner, A. and Kovac, H. (2014) Energetic optimization of foraging honeybees: flexible change of strategies in response to environmental challenges. PLoS ONE 9(8): e105432. DOI: https://doi.org/10.1371 /journal.pone.0105432.

Stabentheiner, A., Vollmann, J., Kovac, H. and Crailsheim, K. (2003) Oxygen consumption and body temperature of active and resting honeybees. J. Insect Physiol. 49: 881-889.

Stabentheiner, A., Kovac, H. and Brodschneider, R. (2010) Honeybee colony thermoregulation - regulatory mechanisms and contribution of individuals in dependence on age, location and thermal stress. PLoS One 5 (1): 113 e 8967.

Stabentheiner, A., Kovac, H., Hetz, S., Käfer, H. and Stabentheiner, G. (2012) Assessing honeybee and wasp thermoregulation and energetics - New insights by combination of flow-through respirometry with infrared thermography. Thermochim. Acta 534: 7786.

Yang, X. and Cox-Foster, D.L. (2007) Effects of parasitization by Varroa destructor on survivorship and physiological traits of Apis mellifera in correlation with viral incidence and microbial challenge. Parasitology 134: 405- 412.

Żółtowska, K., Lipiński, Z. and Dmitryjuk, M. (2005) The total protein content, protein fractions and proteases activities of drone prepupae of Apis mellifera due to varroosis. Wiad. Parazytol. (51) 1: 43-47.

Publisher's note Springer Nature remains neutral with regard to jurisdictional claims in published maps and institutional affiliations. 